\title{
The effect of cochlear implants on phonological acquisition
}

Evaggelia Lazarou, Marianna Hatzopoulou

Department of Logopaedics, Athens Metropolitan College, Greece

https://doi.org/10.36505/ExLing-2010/03/0023/000143

\begin{abstract}
The aim of the present study was to compare the phonological errors that occur in the speech of two 12-year-old Greek children with profound hearing loss. The first child used a cochlear implant (CI) and the second one used hearing aids (HA). The children's phonological development has been assessed using the Phonetic and Phonological Development Test (PPDT), (Levandi et al. 1995) ${ }^{1}$. In alignment with previous studies, the child with HA made more phonological errors than the child with CI, even though some unexpected findings were observed regarding the phonological processes used by both children.
\end{abstract}

Key words: Phonological errors, cochlear implants.

\section{Introduction}

Several researches have examined whether deaf children benefit from a CI in speech production, focusing either on the accuracy of articulating specific sounds (consonants, vowels, clusters), or on the phonological processes used. Regarding the accuracy of articulating consonants, Tobey et al. (1991) and Bouchard et al. (2007) reported that the increase in consonant accuracy resulted in greater speech intelligibility of children with CI, whereas Ertmer et al. (1997) and Tye-Murray and Kirk (1993) found improved and more accurate production of back vowels. However, Chin and Pisoni (2000) stated that back vowels were difficult to produce by a child with CI and Chin and Finnegan (2002) observed distortions of the first segment in clusters production. With regard to phonological processes Chin and Finnegan reported that substitutions of the first segment in clusters production and simplification of either the first or the second segment of consonant clusters were the most common patterns in CI children's speech. Chin and Pisoni (2000) found that final consonant omissions were the most frequent speech errors and Bouchard et al. (2007) recorded substitutions of fricatives by stop consonants (stopping). Focusing on consonant clusters, Chin (2007) observed frequent use of voiceless features instead of voiced sounds (devoicing).

The benefit of HA in the phonological development of profoundly deaf children is investigated in a restricted number of studies, due to the fact that the speech production of deaf children with profound hearing loss is usually very limited. Okalidou (2002) as well as Elfenbeim and Hardin-

ExLing 2010: Proceedings of 3rd Tutorial and Research Workshop on Experimental Linguistics, 25-27 August, Athens, Greece 
Jones (1994) reported frequent distortions of sounds, omissions of consonants in initial, medial or final position of words, cluster simplifications and substitutions, such as devoicing, frontalization and voicing in the speech of deaf children with HA. Finally, no studies were found concerning the comparison of speech in children with CI and HA.

\section{Aim}

The aim of the present study is to investigate:

(a) the types of phonological errors made by profoundly deaf children with $\mathrm{CI}$ and $\mathrm{HA}$,

(b) the effect of CI on phonology acquisition of profoundly deaf children in comparison with the use of HA.

\section{Method}

The subjects of the present study were two 12-year-old prelingually deaf children exposed to Greek: a boy having a CI at his left ear and a girl using two HA; both children have been attending speech and language therapy sessions for 10 years. Children's performance in naming simple pictures and describing complex ones have been assessed with the PPDT (Levandi et al. 1995). Children's elicited answers were audio-taped, transcribed with the IPA symbols and their phonological errors were measured and analyzed.

\section{Results}

The child with CI gave more correct answers than the child with HA in both tasks.

Table 1. Phonological errors made in the tasks of simple and complex pictures.

\begin{tabular}{|l|l|l|l|l|}
\hline \hline Participants & \multicolumn{2}{|l|}{$\begin{array}{l}\text { Ph. errors in naming of } \\
\text { simple pictures }\end{array}$} & $\begin{array}{l}\text { Ph. errors in description of } \\
\text { complex pictures }\end{array}$ \\
\hline & No & $\%$ & No & $\%$ \\
\hline Child with HA & $27 / 70$ & $38.6 \%$ & $8 / 31$ & $25.8 \%$ \\
\hline Child with CI & $9 / 70$ & $12.9 \%$ & $4 / 31$ & $12.9 \%$ \\
\hline \hline
\end{tabular}

In particular, in the task of naming simple pictures, the CI child made less errors $(12.9 \%)$ compared to the errors made by the HA child (38.6\%). Similarly, in the task of describing complex pictures the CI child's errors were less $(12.9 \%)$ compared to those made by the HA child (25.8\%). From Table 1 it becomes obvious that the CI child's performance remained stable in both tasks (12.9\%), whereas in contrast to the expected results the HA child made less errors in the task of describing complex pictures. 
In particular in the task of naming simple pictures, both participants followed similar phonological processes: cluster simplification (HA:10\%, CI:2.9\%), stopping (HA:7.1\%, CI:4.3\%), devoicing (HA:7.1\%, CI:2.9\%) and cluster substitution (HA:1.4\%, CI:1.4\%). However, it was unexpected that omission of final consonant, was found only in the HA child's production (7.1\%) and not in that of the CI child. Furthermore, the CI child made frontalization $(1.4 \%)$, whereas the HA child did not make any errors of that type.

In the task of describing complex pictures it was observed that both participants followed similar phonological processes: devoicing (HA:6.5\%, CI:3.2\%) and cluster substitution (HA:3.2\%, CI:3.2\%). Stopping (9.7\%), omission of final consonant (3.2\%) and consonant substitution with vowel (3.2\%) occurred only in the HA child's answers, whereas cluster simplification $(3.2 \%)$ was made solely by the CI child. However, palatalization (3.2\%) that was observed in the CI child's speech was unexpected.

\section{Discussion}

Overall the profoundly deaf child with CI gave more correct answers and produced less phonological errors than the child with HA. Answering the research question, and in alignment with previous studies (Tobey et al. 1991; Chin and Pisoni 2000), the CI seemed to have a positive effect on the child's speech, since the boy made less phonological errors and demonstrated accuracy in the production of vowels and the majority of consonants. With regard to the type of phonological errors, results showed that both participants used devoicing and cluster substitutions in both tasks, which is in accordance with previous studies (Chin and Pisoni 2000; Bouchard et al. 2007; Chin 2007). Interestingly, no omissions of final consonant occurred in the CI child's speech.

Although the CI child has an advantage over the HA child, he still made mistakes. More specifically, the percentage of errors he made remained stable in both tasks (12.9\%). The results showed that the disadvantage of the HA child over the CI child was obvious. However, what is challenging is that the HA child had improved her performance (25.8\%) in the second task compared to the first task (38.6\%). Concluding, due to the limited number of participants, our outcomes are indicative. For generalizing our findings a larger number of profoundly deaf children with CI and HA is needed. Furthermore, the fact that the error categories of frontalization and palatalization did not occur in the speech of children with CI of the present study is a stimulus for further research. 


\section{Notes}

1. Translation by Lazarou Evaggelia of the Dokimasia Fonitikis kai Fonologikis Exelixis.

\section{References}

Bouchard, M., Le Normand, M., Cohen, H. 2007. Production of consonants by prelinguistically deaf children with cochlear implants. Clinical Linguistics and Phonetics 21, 875-884.

Chin, S.B. 2007. Variation in Consonant Cluster Production by Pediatric Cochlear Implant Users. Ear and Hearing 28, 7S-10S.

Chin, S.B., Finnegan, K.R. 2002. Consonant Cluster Production by Pediatric Users of Cochlear Implants. The Volta Review 102, 157-174.

Chin, S.B., Pisoni, D.B. 2000. A phonological system at 2 years after cochlear implantation. Clinical Linguistics and Phonetics 14, 53-73.

Elfenbeim, J.L., Hardin-Jones, M.A. 1994. Oral communication skills of children who are hard of hearing. Journal of Speech and Hearing Research 37, 216-226.

Ertmer, D.J., Kirk, K.I., Sehgal, S.T., Riley, A.I., Osberger, M.J. 1997. A comparison of Vowel Production by Children with Multichannel Cochlear Implants or Tactile Aids: Perceptual Evidence. Ear and Hearing 18, 307-315.

Levandi, E., Kirpotin, L., Kardamitsi, E., Kabouroglou, M. 1995. Dokimasia Fonitikis kai Fonologikis Exelixis. Omada Erevnas Panelliniou Syllogou Logopedikon.

Okalidou, A. 2002. Barikoia-Kofosi: Meleti tis paragogis tou logou kai therapeutiki paremvasi. Athina: Ellinika Grammata.

Tobey, E. A., Pancamo, S., Staller, S.J., Brimacombe, J.A., Beiter, A.L. 1991. Consonant production of children receiving a multichannel cochlear implant. Ear and Hearing 12, 23-31.

Tye-Murray, N., Kirk, K.I. 1993. Vowel and diphthong production by young users of cochlear implants and the relationship between the phonetic level evaluation and spontaneous speech. Journal of Speech and Hearing Research 36, 488-502. 